\title{
Emerging Implications of Genetic Testing in Inherited Primary Arrhythmia Syndromes
}

\author{
Babken Asatryan, MD, and Argelia Medeiros-Domingo, $M D, P h D$
}

\begin{abstract}
Inherited primary arrhythmia syndromes are genetically determined disorders of cardiac ion channels or ion channel macromolecular complexes usually associated with a higher risk of sudden cardiac death. These conditions have a very broad spectrum of clinical manifestations, ranging from an asymptomatic course to syncope, atrial and ventricular arrhythmias, and conduction disturbances, but may produce sudden infant death syndrome and unexplained sudden cardiac death in apparently healthy individuals. During the last 20 years, the evolving knowledge on the genetic basis of inherited arrhythmia syndromes has dramatically reshaped our understanding of these conditions and, consequently, had a great impact on patient care. Based on the knowledge of the genetic substrates, specific risk factors for individual genotypes have been identified, and various investigations have been launched with the intention of developing a gene- and even mutation-specific therapy. Preliminary results from animal studies suggest that gene therapy rescues the normal ion channel function and thereby prevents cardiac events in some primary arrhythmia syndromes, which suggests that upon appropriate validation in a clinical setting, it may become available for affected patients. The purpose of this review is to provide clinicians with a contemporary insight into the role of genetic testing in the diagnosis, therapy, and prognosis of patients with primary arrhythmia syndromes, and the clinical implications of screening family members who are at risk of sudden cardiac death.
\end{abstract}

Key Words: arrhythmia, ion channels, genetics, sudden death

(Cardiology in Review 2019;27: 23-33)

nherited primary arrhythmia syndromes are genetically determined cardiac diseases caused by mutations in genes encoding cardiac ion channels and associated regulatory proteins (Fig. 1). ${ }^{1}$ These disorders usually follow the Mendelian inheritance pattern, frequently present in the early years of life, and can cause cardiac arrest and/or sudden cardiac death (SCD) among young and apparently healthy individuals. ${ }^{2}$ Genetic testing in these diseases has important implications in diagnosis, prognosis, and therapy. ${ }^{1,3}$ Important features of cardiac channelopathies are variable clinical phenotype and variable expression of the disease in which vulnerability to arrhythmias and disease progression is determined by the multifaceted interplay of the mutation characteristics, epigenetic and environmental factors. ${ }^{4}$ Many of these diseases exhibit overlapping phenotypes, and the precise genetic diagnosis allows specific therapy. The recent advances in next-generation sequencing technologies have provided clinicians and researchers with unique tools to better understand the genetic

From the Department of Cardiology, Inselspital, Bern University Hospital, University of Bern, Bern, Switzerland.

Disclosure: The authors have no conflicts of interest to report.

Supplemental digital content is available for this article. Direct URL citations appear in the printed text and are provided in the HTML and PDF versions of this article on the journal's Web site (www.cardiologyinreview.com).

Correspondence: Argelia Medeiros-Domingo, MD, PhD, Arrhythmias and Cardiogenetics, Department of Cardiology, Inselspital, Bern University Hospital, Freiburgstrasse 10,3010 Bern, Switzerland. E-mail: argelia.medeiros@insel.ch. Copyright (C) 2018 Wolters Kluwer Health, Inc. All rights reserved.

ISSN: $1061-5377 / 19 / 2701-0023$

DOI: $10.1097 /$ CRD.0000000000000203 aspects of these diseases. Here we summarize the current knowledge on genotype-phenotype associations in inherited arrhythmia syndromes, with a focus on important clinical implications of the genetic test in the management of affected patients and their relatives. Due to their controversial impact on clinical application, we did not include in this review the genetic basis of atrial fibrillation (AF) and idiopathic ventricular fibrillation (VF).

\section{LONG QT SYNDROME}

The congenital long QT syndrome (LQTS) is a genetically determined cardiac arrhythmia syndrome characterized by a prolongation of the QT interval on the electrocardiogram (ECG) and an increased propensity to syncope, seizures, polymorphic ventricular tachycardia (VT) (typically, torsades de pointes), cardiac arrest, and SCD in individuals with structurally normal hearts (Fig. 2). ${ }^{5,6}$ The prevalence of congenital LQTS is estimated in the range of $1: 2000-1: 2500$.

\section{Diagnosis of LQTS}

The diagnosis of LQTS relies on symptoms, QT interval duration in the 12-lead ECG corrected for heart rate (QTc), clinical and family history, and genetic test results. ${ }^{8}$ Based on these parameters, Schwartz and Crotti ${ }^{9}$ proposed a scoring system that allows determining the probability of having LQTS (Table 1$).{ }^{9}$ Currently, LQTS is diagnosed in the presence of a QTc interval $\geq 500$ milliseconds, an unequivocally pathogenic mutation in one of the LQTS genes, or a LQTS risk score $\geq 3.5$ in the absence of secondary causes of QTc prolongation. ${ }^{8}$ The diagnosis can also be made in the presence of a QTc between 480 and 499 milliseconds in repeated ECGs in a patient with unexplained syncope, in the absence of a secondary cause for QT prolongation and in the absence of a pathogenic mutation. ${ }^{3,8}$ The diagnosis or exclusion of LQTS solely relying on QTc values should be avoided because nearly $30 \%$ of patients hosting pathogenic mutations in LQTS genes display normal QTc intervals; thus, the Schwartz criteria are an invaluable tool for the selection of candidates for further testing. ${ }^{10}$

\section{Genetics Basis of LQTS and Implications of the Genetic Test in LQTS}

To date, 16 genes have been associated with LQTS (Supplementary Table 1, http://links.lww.com/CIR/A15). The major LQTS genes are $K C N Q 1$ (LQTS1), KCNH2 (LQTS2), and SCN5A (LQTS3), which collectively account for approximately $90 \%$ of all genotype-positive cases. ${ }^{11}$ Nearly $8 \%$ of LQTS patients host compound heterozygous mutations. ${ }^{12}$ Thirteen minor LQTS genes together explain approximately $5-10 \%$ of cases. These include 3 genes that cause multisystem syndromic disorders associated or not associated with prolonged QTc values: ankyrin-B syndrome (ANK2, LQTS4), Andersen-Tawil syndrome (ATS) (KCNJ2, LQTS7), and Timothy syndrome (CACNA1C, LQTS8).

\section{Diagnostic Value}

The yield of genetic testing in LQTS reaches 70-80\% (Fig. 3). ${ }^{13}$ Identification of a clear LQTS-associated mutation in any major gene 

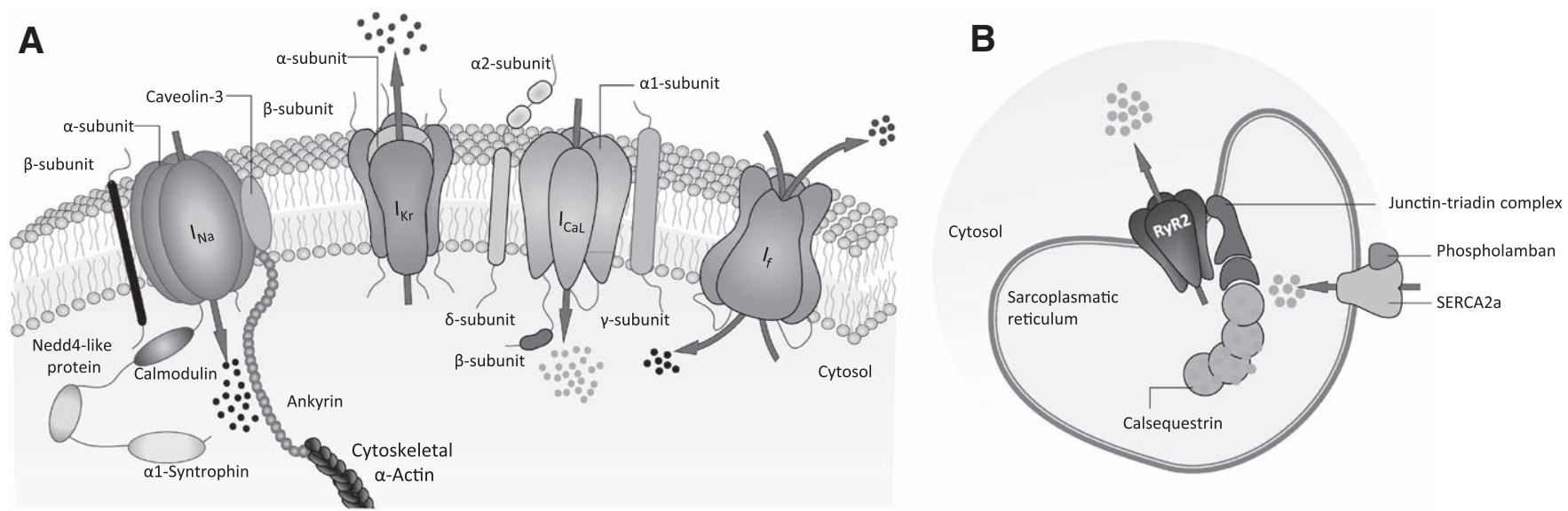

FIGURE 1. Schematic representation of cardiomyocyte ion channel structural elements implicated in the pathogenesis of the cardiac channelopathies. A, The main membrane channels responsible for cardiac action potential. B, Sarcoplasmic calcium-release complex. ATP indicates, adenosine triphosphate; $I_{\mathrm{CaL}^{\prime}}$ calcium current; $\mathrm{I}_{\mathrm{Na}}$, sodium current; $\mathrm{I}_{\mathrm{Kr},}$ rapid component of the delayed rectifier potassium current; $I_{f \prime}$ pacemaker ('funny') current; SERCA2a, sarcoplasmic/endoplasmic reticulum calcium ATPase $2 a$.

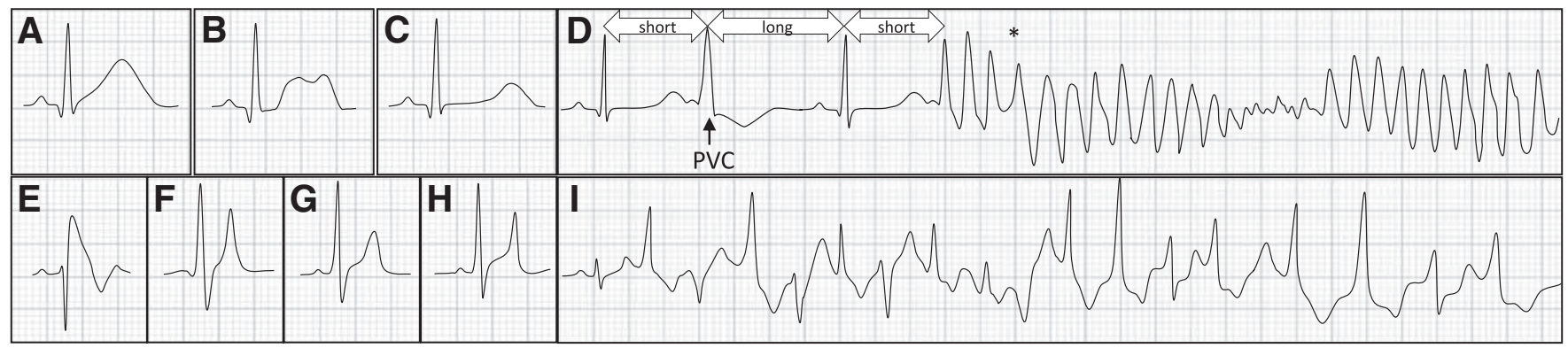

FIGURE 2. Characteristic ECG patterns in inherited primary arrhythmia syndromes. Long QT syndrome type 1-3 (A-C), and torsades de pointes (D); Brugada syndrome (E); short QT syndrome type 1-3 (F-H); and polymorphic (bidirectional) ventricular tachycardia in response to increased exercise load, characteristic for catecholaminergic polymorphic ventricular tachycardia (I). Note the characteristic features of the torsades de pointes arrhythmia: the prolonged QT interval with distorted T-U complex, the arrhythmia initiating short-long-short ventricular cycle sequence triggered by a PVC, the "warm-up" phenomenon with initial R-R cycles longer than subsequent cycles, and the abrupt switching of QRS morphology from predominately positive to predominately negative complexes $\left(^{*}\right)$. ECG indicates electrocardiogram; PVC indicates premature ventricular contraction.

is considered diagnostic, regardless of QTc duration (Table 2). The overall penetrance (proportion of mutation carriers who develop the disease) is estimated to be nearly $40 \%{ }^{14}$ but is reported in the range of 25-100\% among different LQTS subtypes and dependent on mutation localization. ${ }^{15-18}$ Genotyping is particularly important in patients with a high probability of LQTS (Schwartz score, >3). ${ }^{1}$ However, the clinical diagnosis of LQTS will not be swayed by a negative genetic test, which occurs in $20 \%$ of "unquestionable LQTS" (Schwartz score, $\geq 3.5$ ) cases because these patients have a lower risk for arrhythmias than the genotype positives, but have a considerable risk for arrhythmic events. ${ }^{19}$

\section{Genotype-Phenotype Correlation}

LQTS1 (KCNQ1), LQTS5 (KCNE1), and LQTS11 (AKAP9) are caused by defective $\mathrm{I}_{\mathrm{Ks}}$, the slow component of the delayed rectifier potassium current $\left(\mathrm{I}_{\mathrm{K}}\right)$. KCNQ1 and KCNE1 genes encoding respectively the $\alpha$ and $\beta$ subunits of the voltage-gated potassium channel, which conducts the $\mathrm{I}_{\mathrm{Ks}}$ current, whereas A kinase anchoring protein 9 ( $A K A P 9$ ) facilitates the phosphorylation of $K C N Q 1$ by protein kinase $\mathrm{A}$ and thereby augments the $\mathrm{I}_{\mathrm{Ks}}$ current. KCNQ1 is the most common cause of LQTS and accounts for $30-35 \%$ of all genotype-positive cases. Homozygous or compound heterozygous mutations in $K C N Q 1$ or $K C N E 1$ produce autosomal recessive Jervell-Lange-Nielsen syndrome, characterized by severe LQTS phenotype, as evidenced by a QTc $>500$ milliseconds, a high rate of sudden death, and sensorineural deafness. ${ }^{20}$ Patients with LQTS1 typically have a QTc prolongation and broad-based T wave on resting ECG. ${ }^{21} \mathrm{KCNQ} 1$ mutations also account for over $90 \%$ of fetal bradycardias. ${ }^{22}$ Mutations in $K C N Q 1$ predispose affected individuals to arrhythmias during times of physical $(62 \%)$ or emotional duress (26\%) owing to the inability of the cardiomyocytes to adopt (shorten) the repolarization duration to the rising heart rate due to defective $\mathrm{I}_{\mathrm{Ks}}$ current. $^{23}$

LQTS2 $(K C N H 2)$ and LQTS6 $(K C N E 2)$ are caused by defective $\mathrm{I}_{\mathrm{Kr}}$ current, the fast component of $\mathrm{I}_{\mathrm{K}}$. KCNH2 and $K C N E 2$ encode respectively the $\alpha(H E R G)$ and $\beta$ subunits MinK-related peptide 1 (MIRP) of the potassium channel that generate the $\mathrm{I}_{\mathrm{Kr}}$ current. ${ }^{24,25} \mathrm{KCNH} 2$ mutations explain nearly $25-30 \%$ of LQTS cases. The ECG is remarkable for a low-amplitude, notched or biphasic T wave (Fig. 2) ${ }^{21}$ but may be normal in $20 \%$ of $\mathrm{KCNH} 2$ mutation carriers. ${ }^{10}$ Patients with LQTS2 often present with syncope and cardiac arrest in response to emotional stressors (43\%), including unexpected auditory stimuli such as sudden noises and 
TABLE 1. Updated Diagnostic Criteria for Long QT Syndrome Proposed by Schwartz et al ${ }^{9}$

\begin{tabular}{|c|c|}
\hline & Points \\
\hline \multicolumn{2}{|l|}{ Electrocardiographic findings* } \\
\hline \multicolumn{2}{|l|}{ A. QTc† (ms) } \\
\hline$\geq 480$ & 3 \\
\hline $460-479$ & 2 \\
\hline $450-459$ (in males) & 1 \\
\hline $\begin{array}{l}\text { B. QTc } \dagger \text { at the fourth minute of recovery from exercise stress } \\
\text { test } \geq 480 \mathrm{~ms}\end{array}$ & 1 \\
\hline C. Torsade de pointes & 2 \\
\hline D. T wave alternans & 1 \\
\hline E. Notched T wave in 3 leads & 1 \\
\hline F. Low heart rate for age $\S$ & 0.5 \\
\hline \multicolumn{2}{|l|}{ Clinical history } \\
\hline \multicolumn{2}{|l|}{ A. Syncope } \\
\hline With stress & 2 \\
\hline Without stress & 1 \\
\hline B. Congenital deafness & 0.5 \\
\hline \multicolumn{2}{|l|}{ Family history } \\
\hline A. Family members with definite LQTS & 1 \\
\hline $\begin{array}{l}\text { B. Unexplained sudden cardiac death }<30 \text { years of age among } \\
\text { immediate family members }\end{array}$ & 0.5 \\
\hline \multicolumn{2}{|c|}{$\begin{array}{l}\text { Score: } \leq 1 \text { point, low probability of LQTS; } 1.5-3 \text { points, intermediate probability of } \\
\text { LQTS; and } \geq 3.5 \text { points, high probability. } \\
\text { *In the absence of medications or disorders known to affect these electrocardiographic } \\
\text { features. } \\
\text { †QTc calculated by Bazett's formula where QTc }=\text { QT } / \sqrt{R R} \text {. } \\
\text { \$Mutually exclusive. } \\
\text { §Resting heart rate below the second percentile for age. } \\
\text { ๆThe same family member cannot be counted in A and B. } \\
\text { LQTS indicates long QT syndrome; QTc, QT interval duration in the 12-lead } \\
\text { electrocardiogram corrected for heart rate. }\end{array}$} \\
\hline
\end{tabular}

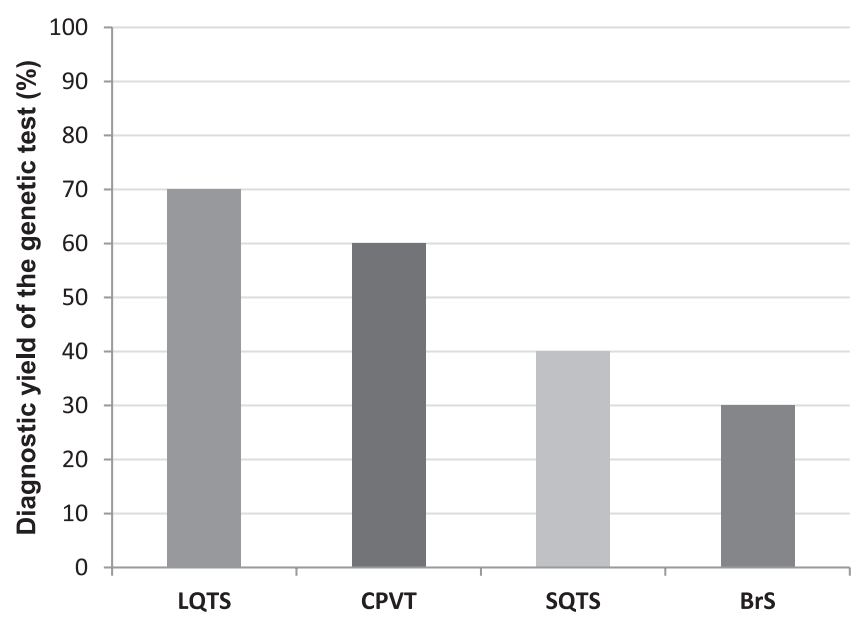

FIGURE 3. Diagnostic yield of the genetic test in primary arrhythmia syndromes. The yield in progressive cardiac conduction disease is not well determined and is therefore not provided. BrS indicates Brugada syndrome; CPVT, catecholaminergic polymorphic ventricular tachycardia; LQTS, long QT syndrome; SQTS, short QT syndrome.

telephone ringing (26\%), particularly when occurring at rest $(64 \%){ }^{23}$ An association of LQTS2 with seizures has been documented. ${ }^{26}$ Women with LQTS2 are particularly at risk in the postpartum period, and during the menopause transition and postmenopausal periods. ${ }^{27}$ In contrast to LQTS1, arrhythmias in LQTS2 are rarely triggered
TABLE 2. Summary of the Clinical Implications of Genetic Testing in the Management of Patients With Primary Arrhythmia Syndrome and Screening of Their Relatives

\begin{tabular}{lcccc}
\hline & $\begin{array}{c}\text { Diagnostic } \\
\text { Value }\end{array}$ & $\begin{array}{c}\text { Prognostic } \\
\text { Value }\end{array}$ & $\begin{array}{c}\text { Therapeutic } \\
\text { Implications }\end{array}$ & $\begin{array}{c}\text { Family } \\
\text { Screening }\end{array}$ \\
\hline LQTS & + & + & + & + \\
CPVT & + & + & + & + \\
BrS & $+/-$ & $+/-$ & - & + \\
SQTS & $+/-$ & - & + & + \\
PCCD & + & $+/-$ & + & + \\
\hline
\end{tabular}

Detailed information on clinical implications and appropriate references can be found in the text.

BrS indicates Brugada syndrome; CPVT, catecholaminergic polymorphic ventricular tachycardia; LQTS, long QT syndrome; PCCD, progressive cardiac conductance disease; SQTS, short QT syndrome.

by exercise $(13 \%)$ and occur twice more frequently while at rest or asleep $(29 \%))^{23}$

There are few cases of LQTS6 reported in the literature; however, no genotype-phenotype segregation has been documented. A recent study has found that $K C N E 2$ variants may be insufficient in isolation to cause LQTS but may confer proarrhythmic susceptibility when provoked by additional QTc modifiers. ${ }^{28}$

LQTS3 (SCN5A), LQTS9 (CAV3), LQTS10 (SCN4B), and LQTS12 (SNTA1) are caused by defective inward late sodium current $\left(\mathrm{I}_{\mathrm{Na}}\right)$. $\mathrm{Na}_{\mathrm{V}} 1.5$ cardiac sodium channel, encoded by $S C N 5 A$, conducts the $\mathrm{I}_{\mathrm{Na}}$ current responsible for phase 0 depolarization. ${ }^{29}$ LQTS3 is caused by heterozygous gain-of-function mutations in the SCN5A and accounts for $5-10 \%$ of genotype-positive LQTS cases. LQTS3 penetrance reaches $90 \% .{ }^{30}$ Gain-of-function mutations in SCN5A prolong the QT interval via small net increase in the $\mathrm{I}_{\mathrm{Na}}$ current. Patients with LQTS3 often experience arrhythmias and cardiac arrest while at rest $(39 \%)$, particularly during sleep when increased vagal tone favors slower heart rate. ${ }^{23}$ In these patients, prolongation of the ST-segment accounts for QT prolongation and is typically followed by a T wave of relatively small amplitude (Fig. 2). ${ }^{21}$

LQTS4 (ANK2) is caused by defective ankyrin-B protein. Loss-of-function mutations in $A N K 2$ abolish the ability of ankyrin$\mathrm{B}$ to restore abnormal calcium dynamics and abnormal localization and expression of $\mathrm{Na} / \mathrm{Ca}$ exchanger, $\mathrm{Na} / \mathrm{K}$ adenosine triphosphate (ATPase), and inositol trisphosphate receptor in cardiomyocytes. ${ }^{31}$ These functional impairments lead to calcium accumulation in the cytoplasm and cause early and delayed after-depolarizations, typically in response to catecholaminergic stimulation. These malfunctions produce varying degrees of cardiac dysfunction, bradycardia, sinus arrhythmia, bidirectional VT, VF, and risk of sudden death, collectively called "ankyrin-B syndrome." These patients have inconsistent and variable QTc prolongation, indicating that ankyrin-B syndrome represents a separate clinical entity with features overlapping with LQTS (LQTS4) and catecholaminergic polymorphic VT (CPVT).

LQTS7/ATS (KCNJ2) is caused by defective Kir2.1, a critical component of the inward rectifier potassium current $\left(\mathrm{I}_{\mathrm{K} 1}\right) .{ }^{32}$ Mutations within $K C N J 2$ cause ATS, ${ }^{33}$ a rare, autosomal dominant disorder $(\approx 1: 500,000)$ characterized by periodic paralysis, mild QTc prolongation, ventricular arrhythmias, and distinctive facial and skeletal dysmorphism. ${ }^{32}$ LQTS occurs in $71 \%$ of patients with $\mathrm{KCNJ} 2$ mutations, whereas periodic paralysis is present in $64 \%$ and dysmorphic features in $78 \%$ of probands. ${ }^{32}$ Cardiac manifestations include premature ventricular contractions, nonsustained polymorphic VT, bidirectional VT, torsades de pointes, cardiac arrest, and sudden death. ${ }^{34}$ Some patients with KCNJ2 mutations exhibit only arrhythmic phenotype. Nearly $73 \%$ of patients with clinical features of ATS and $K C N J 2$ mutations have a prolonged terminal $\mathrm{T}$ wave downslope, 
a wide $\mathrm{T}-\mathrm{U}$ junction, and a biphasic and large $\mathrm{U}$ wave, all reflecting decreased $\mathrm{I}_{\mathrm{K} 1}$ current. $^{34}$

LQTS8/Timothy syndrome (CACNA1C) is caused by defective L-type calcium channel, $\mathrm{Ca}_{\mathrm{v}} 1.2$, which is responsible for the depolarizing calcium current $\left(\mathrm{I}_{\mathrm{CaL}}\right)$. Mutations in $C A C N A 1$ cause Timothy syndrome, a malignant condition characterized by QT prolongation (LQTS8, $<0.5 \%$ of LQTS cases), T wave alternans, lethal arrhythmias, syndactyly, congenital heart disease, immune deficiency, intermittent hypoglycemia, cognitive abnormalities, and autism. ${ }^{35}$ In a study by Splawski et al, ${ }^{35} 10$ of the 17 affected children (59\%) died at a mean age of 2.5 years.

LQTS13 (KCNJ5) is caused by a defective muscarinic-gated $\mathrm{K}+$ channel $\left(\mathrm{I}_{\mathrm{KACh}}\right)$ current. KCNJ5 encodes for the G protein-coupled, inwardly rectifying potassium channel subunit Kir3.4. ${ }^{36}$ Individuals harboring mutations in KCNJ5 exhibit only slightly prolonged QTc but have a greater $\mathrm{T}$ wave morphology combination score based on asymmetry, flatness, and notch, and a reduced low-frequency/highfrequency ratio of heart rate variability as a reflection of cardiac autonomic imbalance. ${ }^{37}$ Only $25 \%$ display a QTc $>480$ milliseconds.

LQTS14 (CALM1), LQTS15 (CALM2), and LQTS16 (CALM3) are caused by defective calmodulin, which modifies the interactions of calcium signal transduction pathway elements with target proteins. In 1 cohort of LQTS patients, calmodulin-related functional variants explained $13 \%$ of cases ${ }^{38}$ Compared with a general LQTS cohort, these patients present earlier in life with more profound QT prolongation, premature cardiac arrest, or sudden death, ${ }^{39,40}$ and may have overlapping features of LQTS and CPVT. ${ }^{38}$

\section{Prognostic Value}

LQTS1 patients $\leq 40$ years of age have been reported to have a higher prevalence of recurrent syncope, aborted cardiac arrest, and sudden death than patients with LQTS2 or LQTS3; however, patients with LQTS3 have a higher lethality of cardiac events, and the cumulative mortality at 40 years of age is similar (6-8\%) among patients with LQTS1 through LQTS3 genotypes. ${ }^{41}$ In the study by Priori et al, ${ }^{10}$ males with either LQTS2 or LQTS3 but not LQTS1 were more likely to become symptomatic before 40 years of age. Cardiac arrest occurred earlier among males with either LQTS1 or LQTS2, than among females. Independent of gender, a QTc $\geq 500$ milliseconds is considered the most important predictor of cardiac events in LQTS1, LQTS2, or LQTS3. ${ }^{10,42}$ The risk for cardiac events also varies among carriers of different variants within the same affected gene. As such, LQTS1 patients with transmembrane mutations exhibited longer QTc intervals and had a higher risk of cardiac events than individuals with C-terminal mutations. ${ }^{17}$ Moss et $\mathrm{al}^{43}$ reported that LQTS2 patients who carry $\mathrm{KCNH} 2$ pore region mutations have a twice higher rate of cardiac events than those with mutations in other regions of $\mathrm{KCNH} 2$. Kapa et $\mathrm{al}^{44}$ showed that nonmissense mutations in $\mathrm{KCNQ1}$, $\mathrm{KCNH} 2$, and SCN5A have a higher probability to cause LQTS (>99\%) regardless of location. In contrast, location appears to be critical for pathogenicity of missense mutations. The corresponding percentage of mutations found in definite cases that would cause LQTS was particularly high, reaching up to $100 \%$ in the transmembrane/linker/pore regions of $\mathrm{KCNH} 2$; the linker, pore, transmembrane, and C-terminus of $K C N Q 1$; and the transmembrane/linker of SCN5A. In a topologybased predictive pathogenicity analysis, Kapplinger et al analyzed the rare variants in the C-terminus of Kv7.1 channel $(K C N Q 1)$ and identified several highly conserved regions (amino acids 349-391, 509-575, and 585-607) with significantly greater risk. ${ }^{18}$

Mutations that lead to dominant-negative effect (alteration in the gene product so it acts antagonistically and out-competes the wildtype protein) on $\mathrm{I}_{\mathrm{Ks}}$ or $\mathrm{I}_{\mathrm{Kr}}$ lead to a more severe LQTS phenotype, as compared to mutations with haploinsufficient behavior. ${ }^{43}$ Such severe phenotype is attributed to the marked alteration of the defective ion channel properties, with or without incomplete intracellular processing and defective trafficking of the channel molecule. Rare variants in $\mathrm{Na}_{\mathrm{V}} 1.5$ localizing to the Domain III/IV (DIII/DIV) interdomain linker have been reported to have a high probability of being pathogenic. ${ }^{45}$

LQTS patients with multiple mutations have been shown to exert more severe phenotype evidenced by longer QTc intervals, higher occurrence of cardiac arrhythmias and a nearly 3.5-fold higher rate of cardiac arrest, as compared to probands with a single or no identified mutation. ${ }^{12}$

\section{Therapeutic Implications}

The 2013 Heart Rhythm Society (HRS), European Heart Rhythm Association (EHRA), and Asia Pacific Heart Rhythm Society (APHRS) Expert Consensus recommends $\beta$-blockers as first-line prophylactic treatment for all mutation carriers (class IIa), except asymptomatics with a QTc $\leq 470$ milliseconds, in whom decisions may be individualized. ${ }^{8} \beta$-Blockers alone can lead to up to a $97 \%$ reduction in cumulative mortality from LQTS1, and to a lower extent from LQTS2. ${ }^{46,47}$

Lifestyle modifications are an important part of managing LQTS patients. Genetically positive patients, regardless of the phenotype, are advised to avoid QT-prolonging medications (www. crediblemeds.org). Patients with LQTS1 and LQTS2 are instructed to avoid emotional stress and vigorous sports activities, particularly swimming for LQTS1, unless an implantable cardioverter defibrillator (ICD) is implanted, whereas those with LQTS3 do not need exercise restriction. However, patients with LQTS3 should be advised to avoid abrupt cessation of rigorous physical exercise, which may cause vagal over-activation and predispose to arrhythmias.

Patients with LQTS2 are recommended to avoid arousal sources, particularly when resting, such as alarm clocks or loud telephones in the bedroom. Fatality risk, however, remains substantially high in patients with Jervell-Lange-Nielsen syndrome, in which conventional doses of $\beta$-blockers have limited efficacy, and ICD therapy is usually indicated. ${ }^{48}$

For many years, the use of $\beta$-blockers in LQTS3 has been controversial. Recent studies have shown that $\beta$-blocker therapy is associated with an $83 \%$ reduction of major cardiac events in females, but not in males (who had fewer events) ${ }^{42}$; however, their use requires vigilance because slow heart rate may induce rate-dependent ventricular arrhythmias. ${ }^{23}$ Nadolol $(1 \mathrm{mg} / \mathrm{kg})$ seems to be the best treatment option for LQTS patients, but unfortunately, it is not available in many countries.

Several sodium channel blockers may be useful in LQTS3. In a recent study, mexiletine shortened the QTc interval and caused a major reduction of life-threatening arrhythmias in LQT3 patients. ${ }^{49}$ However, some mutations have a dual effect on the channel, reduced peak current (loss of function), and increased late current (gain of function); thus, patients with important loss of function may not be candidates to sodium channel blocker therapy. If no functional data are available on the specific variant, it is recommended to perform a drug challenge test under continuous ECG monitoring before prescription of sodium channel blockers to assess both QTc response and the potential proarrhythmic effect or eventual Brugada syndrome (BrS)-type ECG pattern. ${ }^{50,51}$

\section{CATECHOLAMINERGIC POLYMORPHIC VENTRICULAR TACHYCARDIA}

CPVT is an inherited arrhythmic disorder characterized by adrenergically mediated polymorphic or bidirectional VT that may degenerate into VF and cause SCD in patients with structurally normal hearts (Fig. 2).$^{52}$ The prevalence of CPVT is roughly estimated to be 1 in $10,000 .{ }^{53}$ Since the initial description of this severe CPVT phenotype, it has become evident that some patients have 
less aggressive disease and outcome. Nevertheless, when symptoms develop early in life, the prognosis is lethal if untreated.

\section{Diagnosis of CPVT}

CPVT is diagnosed in the presence of exercise- or emotioninduced bidirectional VT, characterized by alternating $180^{\circ}-\mathrm{QRS}$ axis on a beat-to-beat basis, or polymorphic VT in patients with structurally normal hearts and normal resting ECGs; and/or identification of a pathogenic mutation in $R y R 2$ or homozygous mutations in $C A S Q 2 \cdot{ }^{1,8}$ Several cardiovascular conditions may produce clinical features resembling CPVT. Patients with LQTS1 experience exercise-related arrhythmias or syncope. However, they do not have the typical inducible arrhythmias during exercise stress test, as seen in CPVT. Bidirectional VT has also been reported in patients with ATS $^{54}$; however, the prolonged QT interval, prominent U waves, lack of association of arrhythmias with adrenergic triggers, the presence of extracardiac manifestations, and KCNJ2 mutations identified by the genetic test allow us to distinguish ATS from CPVT.

\section{Genetic Basis of CPVT and Implications of the Genetic Test in CPVT}

Known CPVT-associated genes are involved in the calcium homeostasis of cardiac cells. ${ }^{55,56}$ The cardiac ryanodine receptor RyR2 (RyR2) is the principal component of the calcium channel located on the sarcoplasmic reticulum (SR) of cardiomyocytes and functions as the main control for the calcium-induced calcium release. Mutations in $R y R 2$ are found in up to $60 \%$ of patients with strong CPVT phenotype (CPVT1) and autosomal dominant inheritance.$^{57} \mathrm{CASQ} 2$ encodes for cardiac calsequestrin, a luminal calciumbinding glycoprotein that effectively buffers the SR calcium and normally maintains free calcium concentrations below the inhibitory level of SR/endoplasmic reticulum $\mathrm{Ca}^{2+}$ ATPase and, thereby promotes calcium reuptake into the SR. ${ }^{58}$ Compound heterozygous or homozygous CASQ2 mutations account for up to 5\% of CPVT cases (autosomal recessive; CPVT2). ${ }^{1}$ Autosomal dominant inheritance has been reported for CASQ2-CPVT in a single family. ${ }^{59}$ Mutations in $R y R 2$ or $C A S Q 2$ cause uncontrolled calcium release from the SR, which leads to bidirectional or polymorphic VT mediated by delayed after-depolarizations and triggered activity. ${ }^{55}$

Mutations in TRDN, ${ }^{60}$ CALM1, ${ }^{61}$ and CALM3 have been detected in individuals with hallmark features of CPVT, ${ }^{62}$ sometimes in association with prolonged QT intervals. Mutated triadin (TRDN) renders calsequestrin unable to inhibit the RyR2 activity, allowing calcium leaks from the SR and development of clinical features of CPVT, with a recessive mode of transmission. ${ }^{60}$ In 2007, an earlyonset lethal form of CPVT with recessive inheritance in a consanguineous Arab family had been linked to a new locus first mapped on chromosome 7p14-p22, ${ }^{63}$ which had been later corrected and mapped to the TECLR (4q13 locus). ${ }^{64}$ Recently, TECRL and CALM2 mutations have been identified in cardiac arrest survivors with clinical features of both LQTS and CPVT. ${ }^{64,65}$

\section{Diagnostic Value}

The diagnostic yield of genetic test in CPVT is nearly $60 \%$ (Fig. 3). ${ }^{1}$ Testing of at least $R y R 2$ and CASQ2 genes is recommended for patients in whom a clinical index of suspicion has been established. ${ }^{1}$ A positive result, besides confirming the diagnosis, is very useful to identify other affected family members at risk for SCD (Table 2). ${ }^{1,8}$

\section{Genotype-Phenotype Correlation}

Though CPVT typically presents with unremarkable cardiac imaging and baseline ECG, several exceptions have been reported. $R y R 2$ mutation carriers have lower baseline heart rate, and 19\% show sinus bradycardia. ${ }^{66}$ Moreover, a large genomic deletion in exon 3 of $R y R 2$ produced an extended clinical profile including sinoatrial node and atrioventricular dysfunction, AF, atrial standstill, and dilated cardiomyopathy, in addition to the classic CPVT phenotype. ${ }^{67}$ Mutation localization has been associated with severity of the phenotype; mutations in the C-terminal channel-forming domain have been associated with an increased risk for nonsustained VT, whereas central domain mutations have been more frequently associated with supraventricular arrhythmias other than sinus bradycardia. ${ }^{66}$ Studies in CPVT patients with and without $R y R 2$ mutations showed that both groups have average onset of symptoms between 7 and 12 years. ${ }^{52}$ Clinical features of CASQ2- and RyR2-mediated CPVT appear similar; however, because $C A S Q 2$-related cases are very rare, more reliable data may become available with identification of more affected individuals. ${ }^{56}$

\section{Prognostic Value}

When a clear mutation has been identified in $R y R 2$ in an asymptomatic person, it has important prognostic value. The penetrance of $R y R 2$-mediated disease is nearly $83 \% .{ }^{68}$ CPVT patients generally have a poor prognosis if left untreated, as up to $50 \%$ will suffer SCD before 20 years of age ${ }^{69}$ hence undetected CPVT presents a frequent cause of unexplained SCD in the young. ${ }^{70} \mathrm{~A}$ carrier of a heterozygous $C A S Q 2$ mutation confers low or no risk of developing the disease.

\section{Therapeutic Implications}

Family members of CPVT patients, who have a clearly pathogenic mutation in $R y R 2$ or a homozygous/compound heterozygous mutation in $C A S Q 2$, have an indication for treatment with $\beta$-blockers (class IIa). ${ }^{8}$ The recommended $\beta$-blocker is nadolol $1 \mathrm{mg} / \mathrm{kg} .{ }^{8} \mathrm{Know}-$ ing the precise genetic diagnosis allows for the use of certain antiarrhythmic drugs or possibly gene therapy in the near future.

The management of CPVT is based on the following strategies: reducing myocardial adrenergic activation with $\beta$-blockers; preventing spontaneous calcium release from SR and triggered activity; left cardiac sympathetic denervation; and/or ICD as a back-up strategy in high-risk subjects. ${ }^{8}$ Therapy with flecainide prevents ventricular arrhythmias in patients with CPVT not controlled by $\beta$-blockers. ${ }^{71,72}$ In a recent randomized clinical trial, therapy with flecainide plus a $\beta$-blocker significantly reduced ventricular ectopy during exercise compared with placebo plus $\beta$-blocker or a $\beta$-blocker alone. ${ }^{73} \mathrm{KCNJ5}$-mediated CPVT may be more responsive to therapy with flecainide or mexiletine rather than $\beta$-blockers. ${ }^{74}$ In contrast, the protective effect of left cardiac sympathetic denervation has been demonstrated more clearly for patients with $R y R 2$-CPVT than those with CASQ2- or KCNJ5-mediated CPVT. ${ }^{75}$

Gene-specific therapy in animal models of CPVT has been performed with optimistic results. Viral gene transfer of wild-type CASQ2 into the heart of $\mathrm{R} 33 \mathrm{Q}$ mice induced functional long-term expression of calsequestrin, and thereby prevented and reverted severe manifestations of CPVT. ${ }^{76}$ Interestingly, allele-specific silencing by ribonucleic acid interference prevented life-threatening arrhythmias in CPVT mice model carriers of the heterozygous mutation RyR2-R4496C. ${ }^{77}$ These promising findings demonstrate that gene therapy might be an appealing novel therapeutic option for CPVT. Gene therapy is currently being explored at the clinical level.

\section{J WAVE SYNDROMES}

$\mathrm{J}$ wave syndromes consisting of the BrS and early repolarization syndrome (ERS) are described by an accentuation of the J wave on the ECG and life-threatening ventricular arrhythmias. ${ }^{78}$ The early repolarization pattern on the ECG (distinct J-point elevation, or a notch or slur of the terminal part of the QRS with or without an ST-segment elevation) is frequently seen in young and apparently 
healthy individuals, particularly athletes, with a prevalence up to $40 \%$. In most cases, this is a benign ECG feature, ${ }^{78}$ but in some cases, an association with the development of polymorphic VT and VF, both in animals and in humans, has been reported. ${ }^{79,80}$ These findings challenged the benign nature of early repolarization pattern, and it was subsequently referred to as ERS when associated with VT/VF in the absence of apparent heart disease. ${ }^{78} \mathrm{BrS}$ and ERS share similarities with respect to their clinical manifestations and response to pharmacologic therapy, suggesting a similar pathophysiology. ${ }^{78}$ The 2 clinical entities also share a genetic substrate; so far 7 culprit genes have been implicated in ERS, all of which, with the exception of CACNA2D1, have also been linked to BRS. ${ }^{78}$ It is possible that some or all of the knowledge on genetics of $\mathrm{BrS}$ can be helpful for the diagnosis and management of ERS patients and their families. So far, the clinical implications of the genetic test are relatively better established for $\mathrm{BrS}^{78}$; therefore, in this section, we will focus on $\mathrm{BrS}$.

\section{Brugada Syndrome}

$\mathrm{BrS}$ is characterized by a typical ECG pattern of coved-type ST-segment elevation with successive negative $\mathrm{T}$ wave in the right precordial leads $\left(\mathrm{V}_{1}\right.$ to $\left.\mathrm{V}_{3}\right)$ with or without cardiac conduction delays at different levels, and susceptibility to ventricular tachyarrhythmias and SCD (Fig. 2) ${ }^{78}$ BrS frequently manifests in the $3 \mathrm{rd}$ or 4 th decade of life with ventricular arrhythmias or SCD typically occurring during sleep. ${ }^{81}$ The prevalence of BrS is markedly eightfold higher in males, who also have a 3.3-times higher risk for syncope, ICD shock, and SCD than females. ${ }^{81}$ The global prevalence of manifest BrS is estimated at $1-5$ per 10,000 , but the true prevalence might be higher due to an often silent course and intermittent ECG pattern. ${ }^{82}$ The manifest form is more prevalent in Asian and Southeast Asian countries, especially in Japan, Thailand, and the Philippines, where it is the major cause of SCD in the young.

\section{Diagnosis of $\mathrm{BrS}$}

The diagnosis of $\mathrm{BrS}$ is based on its characteristic ECG phenotype (resting 12-lead ECG or provocative drug challenge testing), clinical, and family history. ${ }^{1}$

\section{Genetic Basis of BrS and Implications of the Genetic Test in $\mathrm{BrS}$}

Genetic bases are identified in nearly $30-35 \%$ of $\mathrm{BrS}$ cases (Fig. 3). Mutations in at least 20 genes have been implicated in $\mathrm{BrS} .{ }^{83}$ The majority of BrS cases are sporadic. ${ }^{84}$

Loss-of-function mutations in SCN5A account for about $30 \%$ of $\mathrm{BrS}$ cases, and mutations in other genes collectively account for an additional $5 \% .{ }^{85,86}$ Mutations in $\mathrm{Na}_{\mathrm{v}} 1.5$ interacting proteins, such as its $\beta$-subunit gene, have been shown to cause BrS through their modifier effect on the $\mathrm{Na}_{\mathrm{v}} 1.5$ (SCN5A) function. ${ }^{87-89}$ Mutations in $S C N 10 A, R A N G R F, G P D I L$, and SLMAP independently caused BrS through reducing the $\mathrm{Na}_{\mathrm{v}} 1.5$ surface membrane expression and the $\mathrm{I}_{\mathrm{Na}}$ current. ${ }^{90-93}$ Liu et $\mathrm{al}^{94}$ identified TRPM4 mutations in $6 \%$ of 248 $\mathrm{BrS}$ patients who tested negative for SCN $5 \mathrm{~A}$ mutations. Additionally, Cerrone et $\mathrm{al}^{95}$ found that in some cases, mutations in desmosomal plakophilin 2 (PKP2), which are associated with arrhythmogenic right ventricular cardiomyopathy (ARVC), can be part of the BrS molecular substrate by causing a drastic reduction in $\mathrm{I}_{\mathrm{Na}}$ specifically at the intercalated disc as a result of reduced number of functional channels.

Gain-of-function mutations in potassium channel genes $K C N D 3$ (encodes Kv4.3), KCNE5 (X-linked), and KCNE3 (through interacting with Kv4.3) independently resulted in an increase of the cardiac transient outward potassium current $\left(\mathrm{I}_{\mathrm{to}}\right)$, and produced BrS phenotype in a few cases. ${ }^{96-98} K C N J 8$ and $A B C C 9$ encode Kir6.1 and sulfonylurea receptor subunit $2 \mathrm{~A}$, respectively, which compose the hetero-octameric structure of the ATP-sensitive potassium channel (KATP) channel. ${ }^{99}$ Gain-of-function mutations in $K C N J 8$ or $A B C C 9$ have been reported in association with severe BrS phenotype. ${ }^{100,101}$ Among 236 Japanese BrS patients, 4 probands, of which 3 exhibited short QT interval, were found to have $\mathrm{KCNH} 2$ mutations. ${ }^{102}$

Loss-of-function mutations in calcium channel subunit genes $C A C N A 1 C, C A C N B 2 b$, and $C A C N A 2 D 1$ cause a decrease in the $\mathrm{I}_{\mathrm{Cal}}$ current, resulting in a phenotype of $\mathrm{BrS}$ combined with short QTC interval. ${ }^{103,104}$

Increasing evidence suggests that except for its $S C N 5 A$ mediated type, $\mathrm{BrS}$ is probably an oligogenic disease, ${ }^{105}$ and clinical studies on large cohorts are required to determine the role of the minor genes in the pathogenesis of $\mathrm{BrS}$. It is possible that $\mathrm{BrS}$ represents the final phenotype of multiple pathophysiologic mechanisms sharing the same common pathway. The low penetrance, heterogeneous background, and high proportion of genetically negative BrS cases favor this hypothesis. Recently, several studies have reported a clinical and genetic overlap between $\mathrm{BrS}$ and ARVC as evidenced by ARVC-specific structural and ECG abnormalities and identification of PKP2 mutations in BrS patients, and a BrS-specific ECG pattern in ARVC patients in response to ajmaline challenge test. ${ }^{95,106,107}$ According to Nademanee et al, ${ }^{108}$ the underlying electrophysiologic mechanism of $\mathrm{BrS}$ is delayed depolarization over the anterior aspect of the right ventricular outflow tract epicardium. Catheter ablation over this abnormal area resulted in normalization of the BrS-specific ECG pattern and prevented VT/ VF in high-risk BrS patients. ${ }^{108}$

\section{Diagnostic Value}

Comprehensive or SCN5A genetic testing is considered useful (class IIa) for any patient with clinical suspicion of BrS. Mutationspecific genetic testing is recommended for family members after identification of a causative mutation in the index patient (class I), and allows for presymptomatic diagnosis in relatives at risk who need further clinical follow-up and preventive measures, i.e., antiarrhythmic medications, avoiding drugs with sodium channel blocking activity, avoiding excessive alcohol intake, prompt treatment of fever with antipyretics, etc.

\section{Genotype-Phenotype Correlation}

In a study by Smits et al, ${ }^{109}$ patients with $S C N 5 A$-mediated $\mathrm{BrS}$ had a significantly longer PQ interval and longer His-ventricular conduction time (HV) than patients with non-SCN5A BrS. A PQ interval of $\geq 210$ milliseconds and HV interval of $\geq 60$ milliseconds were predictive for the presence of a $S C N 5 A$ mutation. This finding was validated by a recent study in which BrS patients with $S C N 5 A$ mutations more frequently exhibited conduction abnormalities, than those without. ${ }^{110}$

The exerted ECG pattern can often be a clue for underlying genotype in $\mathrm{BrS}$ patients. Short QT interval often indicates mutations in $C A C N A 1 C$ or $C A C N B 2 b$, or rarely $C A C N A 2 D 1 .{ }^{83,104}$

\section{Prognostic Value}

There are limited and conflicting data on the role of genetics in BrS prognosis. In the France, Italy, Netherlands, Germany (FINGER) BrS registry, SCN5A mutation status was not an independent risk factor for cardiac events (syncope or SCD), ${ }^{111}$ whereas Nishii et $\mathrm{al}^{112}$ and Yamagata et $\mathrm{al}^{110}$ found a significantly higher rate of cardiac events and lower shock-free survival rate in SCN5A mutation carriers. In an analysis considering the mutation types, $\mathrm{BrS}$ patients with a nonsense or frameshift mutation in the SCN5A gene were more likely to develop prolonged PR and QRS intervals (increased conduction delay at different levels in the heart) and present with syncope, than those harboring missense SCN5A mutations. ${ }^{113}$ 


\section{Therapeutic Implications}

Currently, genetic test in BrS has no direct therapeutic implication; however, asymptomatic carriers of clear mutations can be subjected to regular control and can advise about potential arrhythmia triggers.

\section{SHORT QT SYNDROME}

Short QT syndrome (SQTS) is a very rare and highly lethal heritable cardiac channelopathy characterized by brief QT intervals on the ECG and high susceptibility to atrial and ventricular arrhythmias and SCD (Fig. 2). ${ }^{114,115}$ The true incidence is unknown. To date, approximately 100 cases of SQTS have been described. In a recent study, a QTc $\leq 330$ milliseconds has been observed in $0.05 \%$ of the population (using Bazett formula for correction), but these individuals were asymptomatic and had low-to-intermediate risk of SQTS based on clinical and family history. ${ }^{116}$ This suggests that the prevalence of true high-risk SQTS might be even lower. The underlying molecular substrates are short atrial and ventricular refractory periods leading to increased vulnerability to VF. ${ }^{117}$ Patients can present with palpitations or syncope; nevertheless, cardiac arrest at rest can be the first manifestation of the disease in up to $40 \%$ of cases. ${ }^{113}$ Survivors of cardiac arrest have a high recurrence rate of potentially fatal arrhythmias. Male and female genders have similar mortality and prevalence of the disease. ${ }^{115,118}$

Patients with SQTS, regardless of the genetic status, and carriers of SQTS-associated mutations, regardless of QTc duration, commonly exhibit AF. ${ }^{118}$ Interestingly, AF has also been noted in children and adolescents with SQTS; therefore, SQTS should be considered in youngsters with idiopathic (lone) AF.

\section{Diagnosis of SQTS}

Gollob et $\mathrm{al}^{119}$ proposed a diagnostic score to assess the likelihood of having SQTS. The HRS/EHRA/APHRS Expert Consensus suggested the diagnosis of SQTS in the presence of QTc $\leq 330$ milliseconds. ${ }^{8}$ SQTS can also be diagnosed in individuals with a QTc $<360$ milliseconds, who have at least one of the following additional criteria: a pathogenic mutation in culprit genes, family history of SQTS or of SCD by 40 years of age, or survival of a VT/VF episode in the absence of other cardiac disease. ${ }^{8}$ Other ECG characteristics include peaked $\mathrm{T}$ waves in precordial leads with either short or no ST-segment. The QT interval in SQTS is not only too short but also fails to adapt to heart rate with reduced or absent shortening during exercise. $^{117}$

\section{Genetic Basis of SQTS and Implications of the Genetic Test in SQTS}

The first gene described in SQTS was $\mathrm{KCNH2}$ (SQTS1). Mutations in $\mathrm{KCNH} 2$ dramatically increase $\mathrm{I}_{\mathrm{Kr}}$ (opposite to the lossof-function variant in LQTS2), leading to heterogeneous abbreviation of action potential duration and refractoriness, and reduced channel affinity to class III antiarrhythmics. ${ }^{120}$

So far, 5 additional genes have been linked to SQTS. ${ }^{8,121}$ The subtypes SQTS1, SQTS2, and SQTS3 are caused by gainof-function mutations in potassium channel genes $K C N Q 1$, $K C N H 2$, and $K C N J 2,{ }^{120,122,123}$ which are also linked to LQTS2, LQTS1, and LQTS7, respectively, whereas SQTS4, SQTS5, and SQTS6 subtypes are caused by loss-of-function mutations in calcium channel genes and can present as either isolated SQTS $(C A C N A 2 D 1)^{121}$ or clinical features of both $\mathrm{BrS}$ and SQTS (CACNA1C,CACNB2). ${ }^{104} \mathrm{KCNH} 2$ mutations have been described in families with paroxysmal AF and SQTS. ${ }^{124}$ Based on the currently available limited data, the penetrance of SQTS is estimated to be around $80 \% .^{118}$

\section{Diagnostic Value}

The yield of genetic testing has been reported to be nearly $40 \%$ in a combined analysis of all previously reported SQTS cases ${ }^{118}$ but has been lower (23-27\%) in smaller cohorts (Fig. 3). ${ }^{19,125}$ Screening of $K C N H 2, K C N Q 1$, and $K C N J 2$ is recommended as part of the diagnostic evaluation in individuals in whom a clinical suspicion for SQTS has been established based on clinical and family history, and electrocardiographic phenotype. ${ }^{1}$ Mutation-specific screening is recommended in family members of patients with a genetically positive SQTS (Table 2).

\section{Genotype-Phenotype Correlation}

Despite the rarity of SQTS, gene-specific phenotype markers are beginning to emerge. The $\mathrm{T}$ waves tend to be symmetric in SQTS1, but asymmetrical with a less steep ascending limb followed by a rapid descending limb in SQTS2 to SQTS4 (Fig. 2). ${ }^{126}$ In SQTS2, inverted T waves are commonly seen. In SQTS5, a BrS-type ST-elevation in the right precordial leads $\mathrm{V}_{1}$ and/or $\mathrm{V}_{2}$ may be seen at baseline or after administration of sodium channel blockers. ${ }^{26}$

There is no difference in QT duration between gene-specific SQTS groups. ${ }^{118,127}$ Patients with SQTS1 are typically diagnosed during the 4th decade of life, whereas patients with other SQTS genetic profiles usually present before 20 years of age. ${ }^{118}$ SQTS2 patients have a strikingly higher prevalence of sick sinus syndrome and bradycardia (SQTS2: 75\% vs non-SQTS2: 9\%) and AF, compared to non-SQT2 patients (SQT2: 63\%; non-SQTS2: 21\%). ${ }^{118}$

\section{Prognostic Value}

Risk stratification remains the main challenge in SQTS patients. The scoring system of Gollob et $\mathrm{al}^{119}$ unfortunately showed low sensitivity, predicting low probability of arrhythmic events in $63 \%$ of survivors of cardiac arrest in a study by Mazzanti et al. ${ }^{115}$ The uncertainty further increased after 1 study where SQTS patients with QTc $\leq 320$ milliseconds neither had a history of syncope nor familial event, or experienced any fatal cardiac event during a mean follow-up of 5 years. ${ }^{128}$ Another study reported the QTc value as the only risk factor for arrhythmic events in general SQTS population (QTc, $<360 \mathrm{~ms}$ ). ${ }^{125}$ A possible explanation for this discrepancy could be the presence of more malignant founder mutations in the cohort investigated by Mazzanti et al, ${ }^{115}$ but it is more likely that, similar to other channelopathies, gene-gene interactions and posttranslational factors influence the outcome.

\section{Therapeutic Implications}

The genetic test in SQTS is useful mainly for family members; when positive, cascade screening can be performed to detect relatives at risk of SCD. ${ }^{8}$ But so far, no specific therapy is available for the different genetic forms.

\section{PROGRESSIVE CARDIAC CONDUCTION DISEASE}

Progressive cardiac conduction disease (PCCD) is a slow, degenerative process that affects the cardiac conduction system with or without concomitant structural heart disease. ${ }^{129}$ The disease is caused by a progressive alteration in impulse propagation through the His-Purkinje system due to myocardial degeneration, increased collagen turnover in the myocardium and fibrosis in the conduction system, leading to conduction abnormalities at various levels.

\section{Diagnosis of PCCD}

PCCD is diagnosed clinically in the presence of unexplained progressive conduction abnormalities in young individuals $(<50$ years of age). ${ }^{8}$ Imaging modalities such as $2 \mathrm{D}$ echocardiography or cardiac magnetic resonance imaging should be performed to identify 
potential concomitant heart disease. ${ }^{8}$ Genetic testing may be considered (class IIb) in evaluating patients with isolated PCCD or PCCD with concomitant structural heart disease (particularly early-onset forms), especially in the presence of a positive family history of conduction abnormalities, pacemaker implants, or SCD. ${ }^{1,8}$ Mutation-specific genetic testing is recommended (class I) for appropriate relatives after identification of a PCCD-causative mutation in the proband. ${ }^{1}$

\section{Genetic Basis of PCCD and Implications of the Genetic Test in PCCD}

PCCD in structurally normal heart ("isolated PCCD") is caused by mutations in SCN5A, SCN1B, SCN10A, TRPM4, GJA5, and $K C N K 17$. There is a consistent overlap between BrS and PCCD, which can be explained by the shared pathogenesis as indicated by loss-offunction SCN5A mutations. ${ }^{130}$ Mutations in SCN10A (Na 1.8$)$ lead to atrioventricular $(\mathrm{AV})$ conduction defects and $\mathrm{BrS}$ due to its interaction with the promoter of SCN5A. ${ }^{131}$ Additionally, loss-of-function mutations in $S C N 1 B$ can cause $\mathrm{BrS}$ with conduction disease through reduced current density and enhanced slow inactivation of the channel. ${ }^{132}$

Mutations in TRPM4 have been recently implicated in autosomal dominant PCCD. ${ }^{133}$ Makita et al ${ }^{134}$ demonstrated a causal relationship between functional alteration in cardiac gap junction protein connexin-40 (GJA5) and PCCD with malignant ventricular arrhythmias. In 1 patient with PCCD, a germline mutation in GJA5 led to marked reduction of junctional conductance and diffused localization of immunoreactive proteins in the vicinity of the plasma membrane without formation of gap junctions. ${ }^{134}$

PCCD with concomitant structural/congenital heart disease has been previously associated with mutations in genes essential for cardiac morphogenesis. Alteration in $T B X 5$ and $N K X 2.5$ genes has been shown to cause defective expression of connexin- 40 and incomplete development of the specialized conduction system. ${ }^{135}$

\section{Diagnostic Value}

The diagnostic implication of genetic test in PCCD lies in distinguishing genetically mediated disease from acquired forms. Genetic testing in PCCD will also help to identify high-risk patients with potential overlap syndromes and/or those at risk of other cardiac diseases (Table 2).

\section{Genotype-Phenotype Correlation}

SCN5A mutations can produce symptoms early in life, and additional rhythm disturbances such as AF, atrial flutter, or overlap syndrome. ${ }^{136}$ Mutations in NKX2.5 have been reported in association with secundum type atrial septal defect, tetralogy of Fallot, truncus arteriosus, L-transposition of great arteries, double-outlet right ventricle, interrupted aortic arch and hypoplastic left heart syndrome, with or without conduction defects, ${ }^{137}$ ventricular noncompaction, and sudden death. ${ }^{138}$ Mutations in TBX5 cause Holt-Oram syndrome, an autosomal dominant disorder that affects the bones and the heart. ${ }^{139}$ Cardiac manifestations include conduction defects with or without concomitant atrial or ventricular septal defects, bradycardia, or AF.

When PCCD is associated with hypertrophic cardiomyopathy and Wolff-Parkinson-White syndrome, PRKAG2-mediated disease should be suspected. ${ }^{140}$ Mutations in LMNA have been previously associated with PCCD with and without muscular dystrophy and/ or dilated cardiomyopathy. Severe arrhythmias and SCD in these patients may precede the development of cardiomyopathy/muscular dystrophy phenotype. In $L M N A$-mediated disease, progressive atrioventricular block is a risk factor for ventricular arrhythmias. ${ }^{141}$

\section{Prognostic Value}

Meregalli et al ${ }^{113}$ demonstrated a correlation between SCN5A mutation type and the clinical and ECG phenotype in BrS or PCCD probands. Patients with either a truncation mutation or a severe lossof-function missense mutation causing $>90 \%$ reduction in peak $\mathrm{I}_{\mathrm{Na}}$ had a significantly longer PR interval than patients with missense mutations causing $\leq 90 \%$ reduction in peak $\mathrm{I}_{\mathrm{Na}}$. Truncation mutations were associated with a significantly higher rate of syncopal episodes compared with missense mutations. It is also known that GJA5-mediated PCCD has early onset and is associated with premature SCD. ${ }^{134}$ Patients with $L M N A$ mutations and left ventricular dysfunction also have a high risk of SCD. Patients with PRKAG2 mutations may have ventricular preexcitation or the Wolff-Parkinson-White syndrome caused by nodoventricular/fasciculoventricular accessory pathways; therefore, ablation is at high risk for iatrogenic atrioventricular conduction blocks. ${ }^{142}$

\section{Therapeutic Implications}

Due to the overlap with BrS and idiopathic VF, patients with $S C N 5 A$-mediated PCCD should receive active treatment of fever to avoid fever-induced ventricular arrhythmias. Targeted genetic screening of first-degree relatives of genetically positive index patients allows prospective follow-up of asymptomatic mutation carriers.

\section{CONCLUSIONS}

Genetic testing is currently an essential component in the evaluation of patients with suspected inherited arrhythmia syndromes. Understanding the molecular substrate of these diseases improves the diagnosis, allows tailored therapy and better risk stratification. Genetic testing in family members allows the identification of individuals who need further surveillance to prevent SCD, or even lifestyle changes. Ongoing studies are expected to improve the current knowledge on genotype-phenotype correlation in these genetically heterogeneous cardiac diseases, with a promise of individualized, "mutation-specific therapy." The advancement of in vivo experiments will spur the discovery of drugs that target mechanisms underpinning these malignant arrhythmias. The promising results of gene therapy in animal models will optimistically open doors to the development of effective mutation-specific therapies in patients with inherited arrhythmia syndromes.

\section{ACKNOWLEDGMENTS}

The authors acknowledge the Swiss Government Excellence Scholarship for Doctoral Studies awarded to Dr. Asatryan and a research grant from the Swiss Heart Foundation to Dr. Medeiros-Domingo.

\section{REFERENCES}

1. Ackerman MJ, Priori SG, Willems S, et al. HRS/EHRA expert consensus statement on the state of genetic testing for the channelopathies and cardiomyopathies this document was developed as a partnership between the Heart Rhythm Society (HRS) and the European Heart Rhythm Association (EHRA). Heart Rhythm. 2011;8:1308-1339.

2. Chugh SS, Reinier K, Teodorescu C, et al. Epidemiology of sudden cardiac death: clinical and research implications. Prog Cardiovasc Dis. 2008;51:213-228

3. Shen WK, Sheldon RS, Benditt DG, et al. 2017 ACC/AHA/HRS Guideline for the Evaluation and Management of Patients With Syncope: a report of the American College of Cardiology/American Heart Association Task Force on Clinical Practice Guidelines and the Heart Rhythm Society. Circulation. 2017;136:e60-e122

4. Abi Khalil C. The emerging role of epigenetics in cardiovascular disease. Ther Adv Chronic Dis. 2014;5:178-187.

5. Schwartz PJ, Crotti L, Insolia R. Long-QT syndrome: from genetics to management. Circ Arrhythm Electrophysiol. 2012;5:868-877.

6. Drew BJ, Ackerman MJ, Funk M, et al; American Heart Association Acute Cardiac Care Committee of the Council on Clinical Cardiology, the Council on Cardiovascular Nursing, and the American College of Cardiology Foundation. Prevention of torsade de pointes in hospital settings: a scientific statement 
from the American Heart Association and the American College of Cardiology Foundation. Circulation. 2010;121:1047-1060.

7. Schwartz PJ, Stramba-Badiale M, Crotti L, et al. Prevalence of the congenital long-QT syndrome. Circulation. 2009;120:1761-1767.

8. Priori SG, Wilde AA, Horie M, et al. HRS/EHRA/APHRS expert consensus statement on the diagnosis and management of patients with inherited primary arrhythmia syndromes: document endorsed by HRS, EHRA, and APHRS in May 2013 and by ACCF, AHA, PACES, and AEPC in June 2013. Heart Rhythm. 2013;10:1932-1963.

9. Schwartz PJ, Crotti L. QTc behavior during exercise and genetic testing for the long-QT syndrome. Circulation. 2011;124:2181-2184.

10. Priori SG, Schwartz PJ, Napolitano C, et al. Risk stratification in the long-QT syndrome. N Engl J Med. 2003;348:1866-1874.

11. Kapplinger JD, Tester DJ, Salisbury BA, et al. Spectrum and prevalence of mutations from the first 2,500 consecutive unrelated patients referred for the FAMILION long QT syndrome genetic test. Heart Rhythm. 2009;6:1297-1303.

12. Westenskow P, Splawski I, Timothy KW, et al. Compound mutations: a common cause of severe long-QT syndrome. Circulation. 2004;109:1834-1841.

13. Hofman N, Tan HL, Alders M, et al. Yield of molecular and clinical testing for arrhythmia syndromes: report of 15 years' experience. Circulation. 2013;128:1513-1521.

14. Berge KE, Haugaa KH, Früh A, et al. Molecular genetic analysis of long QT syndrome in Norway indicating a high prevalence of heterozygous mutation carriers. Scand J Clin Lab Invest. 2008;68:362-368.

15. Priori SG, Napolitano C, Schwartz PJ. Low penetrance in the long-QT syndrome: clinical impact. Circulation. 1999;99:529-533.

16. Viadero MT, Rubín E, Amigo T, et al. Three generations of hereditary long-QT syndrome with complete penetrance caused by the p.G316E KCNQ1 mutation. Pediatr Cardiol. 2011;32:102-104.

17. Shimizu W, Horie M, Ohno S, et al. Mutation site-specific differences in arrhythmic risk and sensitivity to sympathetic stimulation in the LQT1 form of congenital long QT syndrome: multicenter study in Japan. J Am Coll Cardiol. 2004;44:117-125.

18. Kapplinger JD, Tseng AS, Salisbury BA, et al. Enhancing the predictive power of mutations in the C-terminus of the KCNQ1-encoded KV7.1 voltage-gated potassium channel. J Cardiovasc Transl Res. 2015;8:187-197.

19. Schwartz PJ, Ackerman MJ. The long QT syndrome: a transatlantic clinical approach to diagnosis and therapy. Eur Heart J. 2013;34:3109-3116.

20. Neyroud N, Tesson F, Denjoy I, et al. A novel mutation in the potassium channel gene KVLQT1 causes the Jervell and Lange-Nielsen cardioauditory syndrome. Nat Genet. 1997;15:186-189.

21. Zhang L, Timothy KW, Vincent GM, et al. Spectrum of ST-T-wave patterns and repolarization parameters in congenital long-QT syndrome: ECG findings identify genotypes. Circulation. 2000;102:2849-2855.

22. Cuneo BF, Etheridge SP, Horigome H, et al. Arrhythmia phenotype during fetal life suggests long-QT syndrome genotype: risk stratification of perinatal long-QT syndrome. Circ Arrhythm Electrophysiol. 2013;6:946-951.

23. Schwartz PJ, Priori SG, Spazzolini C, et al. Genotype-phenotype correlation in the long-QT syndrome: gene-specific triggers for life-threatening arrhythmias. Circulation. 2001;103:89-95.

24. Curran ME, Splawski I, Timothy KW, et al. A molecular basis for cardiac arrhythmia: HERG mutations cause long QT syndrome. Cell. 1995;80:795-803.

25. Abbott GW, Sesti F, Splawski I, et al. MiRP1 forms IKr potassium channels with HERG and is associated with cardiac arrhythmia. Cell. 1999;97:175-187.

26. Johnson JN, Hofman N, Haglund CM, et al. Identification of a possible pathogenic link between congenital long QT syndrome and epilepsy. Neurology. 2009;72:224-231.

27. Buber J, Mathew J, Moss AJ, et al. Risk of recurrent cardiac events after onset of menopause in women with congenital long-QT syndrome types 1 and 2 . Circulation. 2011;123:2784-2791.

28. Roberts JD, Krahn AD, Ackerman MJ, et al. Loss-of-function KCNE2 variants: true monogenic culprits of long-QT syndrome or proarrhythmic variants requiring secondary provocation? Circ Arrhythm Electrophysiol. 2017;10:e005282.

29. Wang Q, Shen J, Splawski I, et al. SCN5A mutations associated with an inherited cardiac arrhythmia, long QT syndrome. Cell. 1995;80:805-811.

30. Beaufort-Krol GC, van den Berg MP, Wilde AA, et al. Developmental aspects of long QT syndrome type 3 and Brugada syndrome on the basis of a single SCN5A mutation in childhood. J Am Coll Cardiol. 2005;46:331-337.

31. Mohler PJ, Splawski I, Napolitano C, et al. A cardiac arrhythmia syndrome caused by loss of ankyrin-B function. Proc Natl Acad Sci U S A. 2004;101:9137-9142.
32. Tristani-Firouzi M, Jensen JL, Donaldson MR, et al. Functional and clinical characterization of KCNJ2 mutations associated with LQT7 (Andersen syndrome). J Clin Invest. 2002;110:381-388.

33. Plaster NM, Tawil R, Tristani-Firouzi M, et al. Mutations in Kir2.1 cause the developmental and episodic electrical phenotypes of Andersen's syndrome. Cell. 2001;105:511-519.

34. Zhang L, Benson DW, Tristani-Firouzi M, et al. Electrocardiographic features in Andersen-Tawil syndrome patients with KCNJ2 mutations: characteristic T-Uwave patterns predict the KCNJ2 genotype. Circulation. 2005;111:2720-2726.

35. Splawski I, Timothy KW, Sharpe LM, et al. Ca(V)1.2 calcium channel dysfunction causes a multisystem disorder including arrhythmia and autism. Cell. 2004;119:19-31

36. Yang Y, Yang Y, Liang B, et al. Identification of a Kir3.4 mutation in congenital long QT syndrome. Am J Hum Genet. 2010;86:872-880.

37. Wang F, Liu J, Hong L, et al. The phenotype characteristics of type 13 long QT syndrome with mutation in KCNJ5 (Kir3.4-G387R). Heart Rhythm. 2013;10:1500-1506.

38. Boczek NJ, Gomez-Hurtado N, Ye D, et al. Spectrum and prevalence of CALM1-, CALM2-, and CALM3-encoded calmodulin variants in long QT syndrome and functional characterization of a novel long QT syndrome-associated calmodulin missense variant, E141G. Circ Cardiovasc Genet. 2016;9:136-146.

39. Crotti L, Johnson CN, Graf E, et al. Calmodulin mutations associated with recurrent cardiac arrest in infants. Circulation. 2013;127:1009-1017.

40. Reed GJ, Boczek NJ, Etheridge SP, et al. CALM3 mutation associated with long QT syndrome. Heart Rhythm. 2015;12:419-422.

41. Zareba W, Moss AJ, Schwartz PJ, et al. Influence of the genotype on the clinical course of the long-QT syndrome. International Long-QT Syndrome Registry Research Group. N Engl J Med. 1998;339:960-965.

42. Wilde AA, Moss AJ, Kaufman ES, et al. Clinical aspects of type 3 long-QT syndrome: an international multicenter study. Circulation. 2016;134:872-882

43. Moss AJ, Shimizu W, Wilde AA, et al. Clinical aspects of type-1 long-QT syndrome by location, coding type, and biophysical function of mutations involving the KCNQ1 gene. Circulation. 2007;115:2481-2489.

44. Kapa S, Tester DJ, Salisbury BA, et al. Genetic testing for long-QT syndrome: distinguishing pathogenic mutations from benign variants. Circulation. 2009;120:1752-1760.

45. Kapplinger JD, Giudicessi JR, Ye D, et al. Enhanced classification of Brugada syndrome-associated and long-QT syndrome-associated genetic variants in the SCN5A-encoded $\mathrm{Na}(\mathrm{v}) 1.5$ cardiac sodium channel. Circ Cardiovasc Genet. 2015;8:582-595.

46. Priori SG, Napolitano C, Schwartz PJ, et al. Association of long QT syndrome loci and cardiac events among patients treated with beta-blockers. JAMA. 2004;292:1341-1344.

47. Vincent GM, Schwartz PJ, Denjoy I, et al. High efficacy of beta-blockers in long-QT syndrome type 1: contribution of noncompliance and QT-prolonging drugs to the occurrence of beta-blocker treatment "failures." Circulation. 2009; 119:215-221.

48. Schwartz PJ, Spazzolini C, Crotti L, et al. The Jervell and Lange-Nielsen syndrome: natural history, molecular basis, and clinical outcome. Circulation 2006;113:783-790.

49. Mazzanti A, Maragna R, Faragli A, et al. Gene-specific therapy with mexiletine reduces arrhythmic events in patients with long QT syndrome type 3. J Am Coll Cardiol. 2016;67:1053-1058.

50. Priori SG, Napolitano C, Schwartz PJ, et al. The elusive link between LQT3 and Brugada syndrome: the role of flecainide challenge. Circulation. 2000;102:945-947

51. Giudicessi JR, Ackerman MJ. Genotype- and phenotype-guided management of congenital long QT syndrome. Curr Probl Cardiol. 2013;38:417-455.

52. Priori SG, Napolitano C, Memmi M, et al. Clinical and molecular characterization of patients with catecholaminergic polymorphic ventricular tachycardia. Circulation. 2002;106:69-74.

53. Leenhardt A, Denjoy I, Guicheney P. Catecholaminergic polymorphic ventricular tachycardia. Circ Arrhythm Electrophysiol. 2012;5:1044-1052.

54. Tester DJ, Arya P, Will M, et al. Genotypic heterogeneity and phenotypic mimicry among unrelated patients referred for catecholaminergic polymorphic ventricular tachycardia genetic testing. Heart Rhythm. 2006;3:800-805.

55. Priori SG, Napolitano C, Tiso N, et al. Mutations in the cardiac ryanodine receptor gene (hRyR2) underlie catecholaminergic polymorphic ventricular tachycardia. Circulation. 2001;103:196-200.

56. Lahat H, Pras E, Olender T, et al. A missense mutation in a highly conserved region of CASQ2 is associated with autosomal recessive catecholamineinduced polymorphic ventricular tachycardia in Bedouin families from Israel. Am J Hum Genet. 2001;69:1378-1384. 
57. Bai R, Napolitano C, Bloise R, et al. Yield of genetic screening in inherited cardiac channelopathies: how to prioritize access to genetic testing. Circ Arrhythm Electrophysiol. 2009;2:6-15.

58. Faggioni M, Kryshtal DO, Knollmann BC. Calsequestrin mutations and catecholaminergic polymorphic ventricular tachycardia. Pediatr Cardiol. 2012;33:959-967.

59. Gray B, Bagnall RD, Lam L, et al. A novel heterozygous mutation in cardiac calsequestrin causes autosomal dominant catecholaminergic polymorphic ventricular tachycardia. Heart Rhythm. 2016;13:1652-1660.

60. Roux-Buisson N, Cacheux M, Fourest-Lieuvin A, et al. Absence of triadin, a protein of the calcium release complex, is responsible for cardiac arrhythmia with sudden death in human. Hum Mol Genet. 2012;21:2759-2767.

61. Nyegaard M, Overgaard MT, Søndergaard MT, et al. Mutations in calmodulin cause ventricular tachycardia and sudden cardiac death. Am J Hum Genet. 2012;91:703-712

62. Gomez-Hurtado N, Boczek NJ, Kryshtal DO, et al. Novel CPVT-associated calmodulin mutation in CALM3 (CALM3-A103V) activates arrhythmogenic Ca waves and sparks. Circ Arrhythm Electrophysiol. 2016;9:e004161.

63. Bhuiyan ZA, Hamdan MA, Shamsi ET, et al. A novel early onset lethal form of catecholaminergic polymorphic ventricular tachycardia maps to chromosome 7p14-p22. J Cardiovasc Electrophysiol. 2007;18:1060-1066.

64. Devalla HD, Gélinas R, Aburawi EH, et al. TECRL, a new life-threatening inherited arrhythmia gene associated with overlapping clinical features of both LQTS and CPVT. EMBO Mol Med. 2016;8:1390-1408.

65. Makita N, Yagihara N, Crotti L, et al. Novel calmodulin mutations associated with congenital arrhythmia susceptibility. Circ Cardiovasc Genet. 2014;7:466-474.

66. van der Werf C, Nederend I, Hofman N, et al. Familial evaluation in catecholaminergic polymorphic ventricular tachycardia: disease penetrance and expression in cardiac ryanodine receptor mutation-carrying relatives. Circ Arrhythm Electrophysiol. 2012;5:748-756.

67. Bhuiyan ZA, van den Berg MP, van Tintelen JP, et al. Expanding spectrum of human RYR2-related disease: new electrocardiographic, structural, and genetic features. Circulation. 2007;116:1569-1576.

68. Napolitano C, Priori SG, Bloise R. Catecholaminergic polymorphic ventricular tachycardia. In: Pagon RA, Adam MP, Ardinger HH, et al, eds. GeneReviews(R). Seattle, WA; 2016. Available at: https://www.ncbi.nlm.nih. gov/books/NBK1289/.

69. Leenhardt A, Lucet V, Denjoy I, et al. Catecholaminergic polymorphic ventricular tachycardia in children. A 7-year follow-up of 21 patients. Circulation. 1995;91:1512-1519.

70. van der Werf C, Hofman N, Tan HL, et al. Diagnostic yield in sudden unexplained death and aborted cardiac arrest in the young: the experience of a tertiary referral center in The Netherlands. Heart Rhythm. 2010;7:1383-1389.

71. Watanabe H, Chopra N, Laver D, et al. Flecainide prevents catecholaminergic polymorphic ventricular tachycardia in mice and humans. Nat Med. 2009; $15: 380-383$

72. van der Werf C, Kannankeril PJ, Sacher F, et al. Flecainide therapy reduces exercise-induced ventricular arrhythmias in patients with catecholaminergic polymorphic ventricular tachycardia. J Am Coll Cardiol. 2011;57:2244-2254.

73. Kannankeril PJ, Moore JP, Cerrone M, et al. Efficacy of flecainide in the treatment of catecholaminergic polymorphic ventricular tachycardia: a randomized clinical trial. JAMA Cardiol. 2017;2:759-766.

74. Bökenkamp R, Wilde AA, Schalij MJ, et al. Flecainide for recurrent malignant ventricular arrhythmias in two siblings with Andersen-Tawil syndrome. Heart Rhythm. 2007;4:508-511.

75. Wilde AA, Bhuiyan ZA, Crotti L, et al. Left cardiac sympathetic denervation for catecholaminergic polymorphic ventricular tachycardia. $N$ Engl J Med. 2008;358:2024-2029

76. Denegri M, Bongianino R, Lodola F, et al. Single delivery of an adeno-associated viral construct to transfer the CASQ2 gene to knock-in mice affected by catecholaminergic polymorphic ventricular tachycardia is able to cure the disease from birth to advanced age. Circulation. 2014;129:2673-2681.

77. Bongianino R, Denegri M, Mazzanti A, et al. Allele-specific silencing of mutant mRNA rescues ultrastructural and arrhythmic phenotype in mice carriers of the R4496C mutation in the ryanodine receptor gene (RYR2). Circ Res. 2017;121:525-536.

78. Antzelevitch C, Yan GX, Ackerman MJ, et al. J-Wave syndromes expert consensus conference report: emerging concepts and gaps in knowledge. Heart Rhythm. 2016;13:e295-e324.

79. Gussak I, Antzelevitch C. Early repolarization syndrome: clinical characteristics and possible cellular and ionic mechanisms. J Electrocardiol. 2000;33:299-309.
80. Haïssaguerre M, Derval N, Sacher F, et al. Sudden cardiac arrest associated with early repolarization. N Engl J Med. 2008;358:2016-2023.

81. Benito B, Sarkozy A, Mont L, et al. Gender differences in clinical manifestations of Brugada syndrome. J Am Coll Cardiol. 2008;52:1567-1573.

82. Fowler SJ, Priori SG. Clinical spectrum of patients with a Brugada ECG. Curr Opin Cardiol. 2009;24:74-81.

83. Watanabe H, Minamino T. Genetics of Brugada syndrome. J Hum Genet 2016;61:57-60.

84. Schulze-Bahr E, Eckardt L, Breithardt G, et al. Sodium channel gene (SCN5A) mutations in 44 index patients with Brugada syndrome: different incidences in familial and sporadic disease. Hum Mutat. 2003;21:651-652.

85. Crotti L, Marcou CA, Tester DJ, et al. Spectrum and prevalence of mutations involving BrS1- through BrS12-susceptibility genes in a cohort of unrelated patients referred for Brugada syndrome genetic testing: implications for genetic testing. J Am Coll Cardiol. 2012;60:1410-1418.

86. Kapplinger JD, Tester DJ, Alders M, et al. An international compendium of mutations in the SCN5A-encoded cardiac sodium channel in patients referred for Brugada syndrome genetic testing. Heart Rhythm. 2010;7:33-46.

87. Watanabe H, Koopmann TT, Le Scouarnec S, et al. Sodium channel $\beta 1$ subunit mutations associated with Brugada syndrome and cardiac conduction disease in humans. J Clin Invest. 2008;118:2260-2268.

88. Riuró H, Beltran-Alvarez P, Tarradas A, et al. A missense mutation in the sodium channel $\beta 2$ subunit reveals $\mathrm{SCN} 2 \mathrm{~B}$ as a new candidate gene for Brugada syndrome. Hum Mutat. 2013;34:961-966.

89. Hu D, Barajas-Martinez H, Burashnikov E, et al. A mutation in the beta 3 subunit of the cardiac sodium channel associated with Brugada ECG phenotype. Circ Cardiovasc Genet. 2009;2:270-278.

90. Hu D, Barajas-Martínez H, Pfeiffer R, et al. Mutations in SCN10A are responsible for a large fraction of cases of Brugada syndrome. J Am Coll Cardiol. 2014;64:66-79.

91. Kattygnarath D, Maugenre S, Neyroud N, et al. MOG1: a new susceptibility gene for Brugada syndrome. Circ Cardiovasc Genet. 2011;4:261-268.

92. London B, Michalec M, Mehdi H, et al. Mutation in glycerol-3-phosphate dehydrogenase 1 like gene (GPD1-L) decreases cardiac Na+ current and causes inherited arrhythmias. Circulation. 2007;116:2260-2268.

93. Ishikawa T, Sato A, Marcou CA, et al. A novel disease gene for Brugada syndrome: sarcolemmal membrane-associated protein gene mutation impair intracellular trafficking of hNav1.5. Circ Arrhythm Electrophysiol. 2012;5:1098-1107.

94. Liu H, Chatel S, Simard C, et al. Molecular genetics and functional anomalies in a series of 248 Brugada cases with 11 mutations in the TRPM4 channel. PLoS One. 2013;8:e54131.

95. Cerrone M, Lin X, Zhang M, et al. Missense mutations in plakophilin-2 cause sodium current deficit and associate with a Brugada syndrome phenotype. Circulation. 2014;129:1092-1103.

96. Giudicessi JR, Ye D, Tester DJ, et al. Transient outward current (I(to)) gainof-function mutations in the KCND3-encoded Kv4.3 potassium channel and Brugada syndrome. Heart Rhythm. 2011;8:1024-1032.

97. Ohno S, Zankov DP, Ding WG, et al. KCNE5 (KCNE1L) variants are novel modulators of Brugada syndrome and idiopathic ventricular fibrillation. Circ Arrhythm Electrophysiol. 2011;4:352-361.

98. Delpón E, Cordeiro JM, Núñez L, et al. Functional effects of KCNE3 mutation and its role in the development of Brugada syndrome. Circ Arrhythm Electrophysiol. 2008;1:209-218.

99. Inagaki N, Gonoi T, Clement JP 4th, et al. Reconstitution of IKATP an inward rectifier subunit plus the sulfonylurea receptor. Science. 1995;270:1166-1170.

00. Medeiros-Domingo A, Tan BH, Crotti L, et al. Gain-of-function mutation S422L in the KCNJ8-encoded cardiac K(ATP) channel Kir6.1 as a pathogenic substrate for J-wave syndromes. Heart Rhythm. 2010;7:1466-1471.

101. Hu D, Barajas-Martínez H, Terzic A, et al. ABCC9 is a novel Brugada and early repolarization syndrome susceptibility gene. Int $J$ Cardiol. 2014; $171: 431-442$

102. Wang QI, Ohno S, Ding WG, et al. Gain-of-function KCNH2 mutations in patients with Brugada syndrome. J Cardiovasc Electrophysiol. 2014;25:522-530.

103. Burashnikov E, Pfeiffer R, Barajas-Martinez H, et al. Mutations in the cardiac L-type calcium channel associated with inherited J-wave syndromes and sudden cardiac death. Heart Rhythm. 2010;7:1872-1882.

104. Antzelevitch C, Pollevick GD, Cordeiro JM, et al. Loss-of-function mutations in the cardiac calcium channel underlie a new clinical entity characterized by ST-segment elevation, short QT intervals, and sudden cardiac death Circulation. 2007;115:442-449. 
105. Le Scouarnec S, Karakachoff M, Gourraud JB, et al. Testing the burden of rare variation in arrhythmia-susceptibility genes provides new insights into molecular diagnosis for Brugada syndrome. Hum Mol Genet. 2015;24:2757-2763.

106. Catalano O, Antonaci S, Moro G, et al. Magnetic resonance investigations in Brugada syndrome reveal unexpectedly high rate of structural abnormalities. Eur Heart J. 2009;30:2241-2248.

107. Peters S, Trümmel M, Denecke S, et al. Results of ajmaline testing in patients with arrhythmogenic right ventricular dysplasia-cardiomyopathy. Int $J$ Cardiol. 2004;95:207-210.

108. Nademanee K, Veerakul G, Chandanamattha P, et al. Prevention of ventricular fibrillation episodes in Brugada syndrome by catheter ablation over the anterior right ventricular outflow tract epicardium. Circulation. 2011;123:1270-1279.

109. Yamagata K, Horie M, Aiba T, et al. Genotype-phenotype correlation of SCN5A mutation for the clinical and electrocardiographic characteristics of probands with Brugada syndrome: a Japanese multicenter registry. Circulation. 2017;135:2255-2270.

110. Smits JP, Eckardt L, Probst V, et al. Genotype-phenotype relationship in Brugada syndrome: electrocardiographic features differentiate SCN5Arelated patients from non-SCN5A-related patients. J Am Coll Cardiol. 2002;40:350-356.

111. Probst V, Veltmann C, Eckardt L, et al. Long-term prognosis of patients diagnosed with Brugada syndrome: results from the FINGER Brugada Syndrome Registry. Circulation. 2010;121:635-643.

112. Nishii N, Ogawa M, Morita H, et al. SCN5A mutation is associated with early and frequent recurrence of ventricular fibrillation in patients with Brugada syndrome. Circ J. 2010;74:2572-2578.

113. Meregalli PG, Tan HL, Probst V, et al. Type of SCN5A mutation determines clinical severity and degree of conduction slowing in loss-of-function sodium channelopathies. Heart Rhythm. 2009;6:341-348.

114. Gussak I, Brugada P, Brugada J, et al. Idiopathic short QT interval: a new clinical syndrome? Cardiology. 2000;94:99-102.

115. Mazzanti A, Kanthan A, Monteforte N, et al. Novel insight into the natural history of short QT syndrome. J Am Coll Cardiol. 2014;63:1300-1308.

116. Providência R, Karim N, Srinivasan N, et al. Impact of QTc formulae in the prevalence of short corrected QT interval and impact on probability and diagnosis of short QT syndrome. Heart. 2018;104:502-508.

117. Gaita F, Giustetto C, Bianchi F, et al. Short QT syndrome: a familial cause of sudden death. Circulation. 2003;108:965-970.

118. Harrell DT, Ashihara T, Ishikawa T, et al. Genotype-dependent differences in age of manifestation and arrhythmia complications in short QT syndrome. Int J Cardiol. 2015;190:393-402.

119. Gollob MH, Redpath CJ, Roberts JD. The short QT syndrome: proposed diagnostic criteria. J Am Coll Cardiol. 2011;57:802-812.

120. Brugada R, Hong K, Dumaine R, et al. Sudden death associated with shortQT syndrome linked to mutations in HERG. Circulation. 2004;109:30-35.

121. Templin C, Ghadri JR, Rougier JS, et al. Identification of a novel loss-offunction calcium channel gene mutation in short QT syndrome (SQTS6). Eur Heart J. 2011;32:1077-1088.

122. Bellocq C, van Ginneken AC, Bezzina CR, et al. Mutation in the KCNQ1 gene leading to the short QT-interval syndrome. Circulation. 2004;109:2394-2397.

123. Priori SG, Pandit SV, Rivolta I, et al. A novel form of short QT syndrome (SQT3) is caused by a mutation in the KCNJ2 gene. Circ Res. 2005;96:800-807.
124. Hong K, Bjerregaard P, Gussak I, et al. Short QT syndrome and atrial fibrillation caused by mutation in KCNH2. J Cardiovasc Electrophysiol. 2005;16:394-396.

125. Giustetto C, Schimpf R, Mazzanti A, et al. Long-term follow-up of patients with short QT syndrome. J Am Coll Cardiol. 2011;58:587-595.

126. Zareba W, Cygankiewicz I. Long QT syndrome and short QT syndrome. Prog Cardiovasc Dis. 2008;51:264-278.

127. Borggrefe M, Wolpert C, Antzelevitch C, et al. Short QT syndrome. Genotype-phenotype correlations. $J$ Electrocardiol. 2005;38(4 suppl):75-80.

128. Dhutia H, Malhotra A, Parpia S, et al. The prevalence and significance of a short QT interval in 18,825 low-risk individuals including athletes. $\mathrm{Br} J$ Sports Med. 2016;50:124-129.

129. Lynch HT, Mohiuddin S, Sketch MH, et al. Hereditary progressive atrioventricular conduction defect. A new syndrome? JAMA. 1973;225:1465-1470.

130. Schott JJ, Alshinawi C, Kyndt F, et al. Cardiac conduction defects associate with mutations in SCN5A. Nat Genet. 1999;23:20-21.

131. van den Boogaard M, Smemo S, Burnicka-Turek O, et al. A common genetic variant within SCN10A modulates cardiac SCN5A expression. J Clin Invest. 2014;124:1844-1852.

132. Kruse M, Schulze-Bahr E, Corfield V, et al. Impaired endocytosis of the ion channel TRPM4 is associated with human progressive familial heart block type I. J Clin Invest. 2009;119:2737-2744.

133. Makita N, Seki A, Sumitomo N, et al. A connexin40 mutation associated with a malignant variant of progressive familial heart block type I. Circ Arrhythm Electrophysiol. 2012;5:163-172.

134. $\mathrm{Hu} \mathrm{D}$, Barajas-Martinez $\mathrm{H}$, Medeiros-Domingo $\mathrm{A}$, et al. A novel rare variant in SCN1Bb linked to Brugada syndrome and SIDS by combined modulation of $\mathrm{Na}(\mathrm{v}) 1.5$ and $\mathrm{K}(\mathrm{v}) 4.3$ channel currents. Heart Rhythm. 2012;9:760-769.

135. Jay PY, Harris BS, Maguire CT, et al. Nkx2-5 mutation causes anatomic hypoplasia of the cardiac conduction system. J Clin Invest. 2004;113:1130-1137.

136. Tan $\mathrm{BH}$, Iturralde-Torres $\mathrm{P}$, Medeiros-Domingo $\mathrm{A}$, et al. A novel C-terminal truncation SCN5A mutation from a patient with sick sinus syndrome, conduction disorder and ventricular tachycardia. Cardiovasc Res. 2007;76:409-417.

137. McElhinney DB, Geiger E, Blinder J, et al. NKX2.5 mutations in patients with congenital heart disease. J Am Coll Cardiol. 2003;42:1650-1655.

138. Ouyang P, Saarel E, Bai Y, et al. A de novo mutation in NKX2.5 associated with atrial septal defects, ventricular noncompaction, syncope and sudden death. Clin Chim Acta. 2011;412:170-175.

139. Basson CT, Bachinsky DR, Lin RC, et al. Mutations in human TBX5 [corrected] cause limb and cardiac malformation in Holt-Oram syndrome. Nat Genet. 1997;15:30-35.

140. Arad M, Benson DW, Perez-Atayde AR, et al. Constitutively active AMP kinase mutations cause glycogen storage disease mimicking hypertrophic cardiomyopathy. J Clin Invest. 2002;109:357-362.

141. Hasselberg NE, Edvardsen T, Petri H, et al. Risk prediction of ventricular arrhythmias and myocardial function in lamin $\mathrm{A} / \mathrm{C}$ mutation positive subjects. Europace. 2014;16:563-571.

142. Thevenon J, Laurent G, Ader F, et al. High prevalence of arrhythmic and myocardial complications in patients with cardiac glycogenosis due to PRKAG2 mutations. Europace. 2017;19:651-659. 